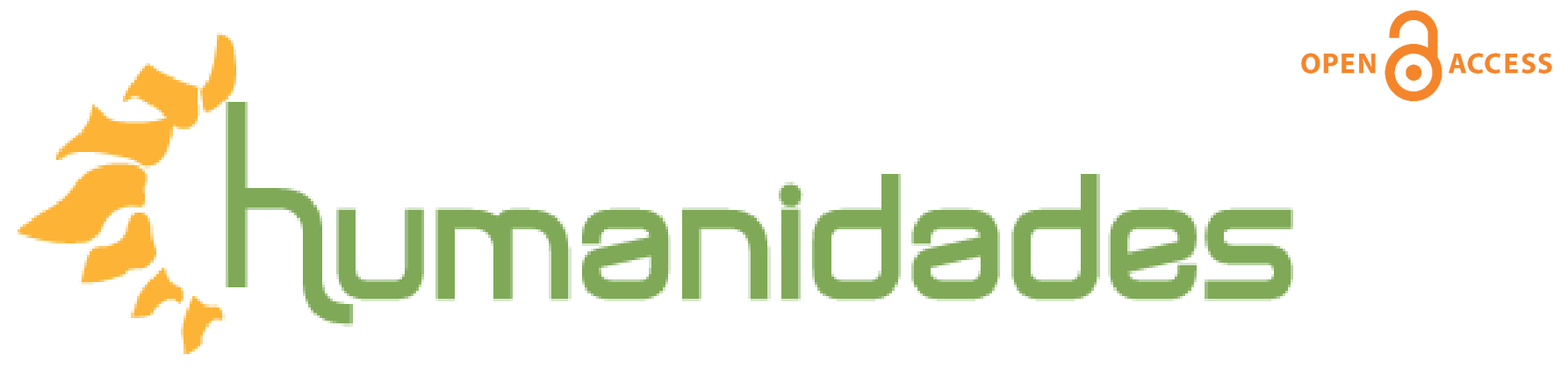

Revista de la Escuela de Estudios Generales, Universidad de Costa Rica

Enero-junio, 2018 •Volumen 8, número 1 • EISSN 2215-3934 •pp. 137-151

Recibido: 28-Septiembre-2017 Aceptado:18-Diciembre-2017

\title{
Leer, asumir y etiquetar al Otro: una lectura de "Héroes a medio tiempo" de Justo Arroyo
}

DOI: http://dx.doi.org/10.15517/h.v8i1.31475

\section{Máster Shirley Longan Phillips}

Universidad de Costa Rica, Escuela de Estudios Generales, Costa Rica.

Correo electrónico: shirley.longan@ucr.ac.cr

Todos los derechos reservados. Universidad de Costa Rica. Esta revista se encuentra licenciada con Creative Commons. Reconocimiento-NoComercial-SinObraDerivada 3.0 Costa Rica. Correo electrónico: humanidades@ucr.ac.cr / Sitio web: http://revistas.ucr.ac.cr/index.php/ humanidades 


\section{Leer, asumir y etiquetar al Otro: una lectura de "Héroes a medio tiempo" de Justo Arroyo}

\section{Resumen}

"Héroes a medio tiempo" es el último de los cuentos de un libro homónimo del escritor panameño Justo Arroyo, ganador del Premio Centroamericano de Literatura "Rogelio Sinán" 1997-1998. El objetivo de este artículo es hacer una lectura de este cuento a partir de la construcción del Otro, según la propuesta de Luis Villoro. El texto es contado por un narrador protagonista egocéntrico y despechado que quiere estar solo para rumiar su propia desgracia. Pero, aparece un hombre de talle bajo que le da un vuelco a la historia: el protagonista empieza a leerlo y etiquetarlo, es decir, lo construye como Otro. Sin embargo, también aparece un diálogo, forzado al principio, que mueve en su lugar de discurso al "imponente" narrador, quien sale del bar sobrio, sin dolor y con un nuevo amigo. La conclusión de este artículo es que el protagonista llega al tercer y último estadio del reconocimiento del Otro, pues el dolor hermana a estos dos hombres, en apariencia, tan disímiles.

\section{Read, Assume, and Label the Other: \\ a Reading of the Short Story "Héroes a medio tiempo" by Justo Arroyo}

\begin{abstract}
"Heroes a meido tiempo" is a short story of the Panamanian writer Justo Arroyo, winner of the Prize Premio Centroamericano de Literatura "Rogelio Sinán" 1997-1998. The objective of this paper is to read this short story from the perspective of the construction of the Other, by Luis Villoro. The text is told by an egocentric narrator who wants to be alone to ruminate about his own disgrace. However, a second man arrives and twists the story: the protagonist starts to read and label him; in other words, he constructs the second one as Other. Nevertheless, a dialogue arrives, forced at the beginning, which moves this "imponent" narrator from his discourse place. He goes out the bar sober, painless and with a new friend. The conclusion of this paper is that the protagonist arrives at the third and last stage of recognition of the Other because the pain has shortened the space between these two men, who are, just apparently, different.
\end{abstract}

Palabras claves: Identidad, Otredad, "Héroes a medio tiempo", Justo Arroyo, literatura panameña 
Leer, asumir y etiquetar al Otro...

"Héroes a medio tiempo" es el último de los cuentos de un libro homónimo del escritor panameño Justo Arroyo, ganador del Premio Centroamericano de Literatura "Rogelio Sinán" 1997-1998. El cuento en estudio trata de un hombre que llega a un bar para olvidar las penas, dispuesto a tomar, durante toda la noche, cien whiskys pues quiere estar solo, pero no en su casa, pues el dolor es más manejable anestesiado con licor. En el whisky número veinte entra otro hombre, más pequeño, un hombre de talla baja. El protagonista inmediatamente empieza a leerlo y etiquetarlo: hombrecito, gnomo, duende, enano. Seguidamente, este segundo hombre empieza a hablar de dolor. El protagonista no desea mantener esta conversación, sin embargo, lo escucha y este hecho le abre un mundo totalmente distinto al que se había imaginado. El objetivo de este artículo es hacer una lectura de este cuento, siguiendo la lógica del mismo texto y la construcción que se hace de los personajes a partir del tema de la construcción del Otro.

\section{Del autor y del texto}

Justo Arroyo es un escritor panameño sumamente laureado. Ha recibido premios como los Juegos Florales Centroamericanos (Guatemala) con su primera novela; en varias ocasiones ha ganado el Concurso Literario "Ricardo Miró" y Obtuvo el Premio "Pluma de Oro" de la Cámara Panameña del Libro, en el año 2000 ganó el premio César Candenedo de cuento y fue escogido como Escritor del año por la Cámara Panameña del Libro. En febrero del 2014 fue aceptado como miembro de la Academia Panameña de la Lengua y en este año 2017 fue condecorado con el Premio "Pluma de Oro" nuevamente. Ha sido Jurado del Concurso Casa de las Américas, de Cuba. Y, la Universidad Simón Bolívar de Colombia le otorgó un Doctorado Honoris Causa

El libro Héroes a medio tiempo (1998) es una colección de once cuentos, algunos de ellos aparecen en antologías prestigiosas, por ejemplo, el primero "La pregunta" aparece en El cuento hispanoamericano (2007) de Seymor Menton; "La ofrenda" en Cuentos panameños: antología de narrativa panameña contemporánea (2004) de la Editorial Popular y el cuento en estudio "Héroes a medio tiempo" abre la antología Cicatrices: retrato del cuento centroamericano (2004) del compilador Werner Mackenbach. 


\section{Breve perspectiva para este análisis}

Analizar la construcción del Otro es un tema que expone Luis Villoro en el texto "Estadios en el reconocimiento del otro", en el cual establece tres niveles de acercamiento. El primer nivel consiste en reconocer la otredad y objetivarla, convertirla, literalmente, en "cosa" para acercarse a ella. El segundo nivel se da cuando "el otro es sujeto de derechos, pero no de significados... [se] reconoce la igualdad del otro, pero no su plena diferencia" (Villoro, 1998:159); y el tercer estadio "sería el reconocimiento del otro a la vez en su igualdad y en su diversidad" (Villoro, 1998:160).

\section{Leer al Otro}

El cuento "Héroes a medio tiempo" empieza con un narrador protagonista muy particular:

Después de lo que míl había ocurrido, no estaba de humor para hablar con nadie. Lo único que deseaba era una larga sesión de tragos para intentar olvidar. En el bar, me dirigí a la esquina más apartada y le pedí al cantinero el primero de los cien whiskys que pensaba bajar esa noche. Y me lo trajo tal cual yo quería, sin comentario alguno, dejándome solo con mi dolor (Arroyo, 1998: p.111).

Un narrador protagonista es explicado por Pickering y Durham como un narrador en primera persona. Este tipo de narrador da otra forma de restricción a la voz que cuenta la historia: se dirige directamente al lector, sin intermediario. Este personaje se refiere a sí mismo(a) como "yo" en la historia. Este narrador de primera persona controla y limita el acceso de información, pero es libre de especular, puede reportar lo que sabe de primera mano o lo que le han contado otros personajes, también puede contar historias en retrospectiva, mirando hacia un período de tiempo donde las aventuras ya han concluido, o que haya sido asignada la tarea de contar la historia de alguien más.

El narrador en primera persona es necesariamente subjetivo: solo sus pensamientos y sentimientos son penetrados directamente, es decir, el lector jamás puede observar las situaciones o a los otros personajes "como realmente son" porque siempre está la mediación consciente de ese "yo". Sin embargo, esta clasificación es muy amplia. 
En este caso aparece un narrador protagonista sumamente egocéntrico, lo cual se destaca en todas las formas que utiliza que están relacionadas con la primera persona singular, pero con un gran énfasis en ella, pues busca enfatizar la apropiación de su espacio en el bar. El texto continúa con la descripción que hace el protagonista de su dolor, cabe resaltar la comparación con el boxeo, y su intención de sedarlo y anestesiarlo con licor:

Al quinto trago, el dolor se hizo menos intenso pero parecía haberse refugiado en algún lugar del pecho, como esos boxeadores que se amarran al contrincante cuando los suenan de verdad y esperan que se les pase el aturdimiento para volver con más ganas. Así sentía el dolor dentro de mí, mareado pero no noqueado, acumulando fuerzas para regresar (Arroyo, 1998: p.111).

Seguidamente, al décimo whisky, según la contabilidad que lleva el protagonista, hace una primera lectura del cantinero, y luego fija su mirada en "la belleza de las botellas o la música de la rockola", es en este espacio donde encuentra un respiro para el dolor. Con esto hace una lectura del ambiente del bar donde se encuentra, y mientras él suda a mares, y el calor es el recordatorio del dolor, los demás parecen no sufrir este problema.

Con el trago número quince, el narrador sigue en su lectura del cantinero, quién según su opinión él ya debería estar totalmente borracho. Según su autolectura, el narrador piensa que no hay ningún problema, pues él es capaz de controlar la situación

Pero no tenía nada de qué preocuparse, porque aun en mis momentos de borrachera extrema, transmito una apariencia de absoluta sobriedad, con una mirada limpia que enmascara la total ausencia de mi cerebro. Y de la misma forma puedo caminar o manejar, sin la menor vacilación, seguro entre cualquier tránsito para, al despertar al día siguiente, no tener la más remota idea de cómo llegué a casa ni por qué calles conduje. Y ha debido ser esta mirada serena lo que lo convenció de que podía seguir sirviéndome [...] Porque si existe algo que me ha salvado del alcoholismo es el alcohol mismo, que me repugna de día. De día, no soy capaz ni de una cerveza, pero cuando llega la noche es otra cosa (Arroyo, 1998 p. 112).

Y, es en la siguiente reflexión donde se puede intuir cuál es el dolor que aqueja a este protagonista: "Mi temor era estar solo. Encontrarme en cama mirando el cielo raso 
y tener que afrontar el dolor" (Arroyo, 1998: p.112) todo aparenta que es un mal de amores, pues antes había dicho que el dolor lo tenía en el pecho. El bar y los whiskys eran la forma de anestesiar este dolor.

En eso llega un párrafo supremamente potente en el cuento, probablemente el más potente pues es el que quiebra la historia y en una sola línea marca el punto de giro: "Con el whisky número veinte entró" (Arroyo, 1998: p. 113). Aquí, lo primero que sucede es que el protagonista empieza a leer a este otro hombre que entra al bar, luego asume su vida y empieza a etiquetarlo mentalmente. Al protagonista le molesta no tanto por su tamaño, sino por haber invadido su espacio en el bar:

Era un hombre muy pequeño, parecido a un gnomo, y cuando se sentó en un taburete, al lado mío, los dos pies le quedaron colgando, bien lejos del suelo. Yo seguí mirando hacia adelante, como para no aceptar su presencia, pero por la esquina del ojo pude ver su sonrisa, una sonrisa traviesa que acentuaba aún más su apariencia de duende. [...] Entonces pidió un trago y empezó a jugar con el taburete, meciéndose, hacia adelante y hacia atrás, hacia la izquierda y hacia la derecha, realizando incluso circunferencias y en efecto divirtiéndose... como un enano (Arroyo, 1998: p. 113).

En palabras de Villoro, el protagonista se encuentra en el primer estadio del reconocimiento del Otro. A él no le interesa conocerlo, por lo tanto, lo invisibiliza; así, de esta forma, el protagonista intenta ignorarlo. La lectura que ha hecho hasta este momento es una lectura desde los estereotipos, desde lo establecido y lo esperado: del "orden de las cosas" para usar las palabras de Pierre Bourdieu. Incluso, es remarcado con la última frase, recogida por el Diccionario de la Real Academia como una locución adverbial coloquial: "Me divertí como un enano", la cual refuerza la lectura preconcebida que hace el protagonista de este otro ser humano. En el esfuerzo de ignorar al Otro (el hombre que entró en el whisky número veinte), el protagonista, desde los estereotipos, hace una lectura del cantinero:

Yo seguí con la vista adelante, toda mi concentración en mantener el dolor bajo control, entreteniéndome con la madera del bar o la variedad de licores o la barriga del cantinero o su deleite al confeccionar tragos. Especialmente cuando le pedían cocteles. Entonces el rostro se le iluminaba y el cuerpo de elefante parecía bailar al preparar las mezclas. Su satisfacción plena llegaba al concluir una obra maestra, llena de colores, frutas y paragüitas que colocaba con una venia frente al cliente. 
Leer, asumir y etiquetar al Otro...

Todo lo contrario a cuando le pedían una simple cerveza o una soda, cuando atendía con displicencia (Arroyo, 1998: p.114).

Seguidamente, el protagonista hace una descripción del tipo de trago que está tomando, y cómo su apreciación de la proporción que el cantinero le servía se convertía en una suerte de comunicación con este: "El cantinero y yo estábamos sobre la misma onda, [...] yo degustando su pericia en silencio, él disfrutando mi aprobación en silencio (Arroyo, 1998: 114). De la cita anterior sobresale que, por primera vez, el protagonista habla en primera persona plural. Pero, ese "nosotros" al que se refiere, en realidad es muy poco inclusivo con el cantinero, pues el texto no recoge ninguna de las conversaciones sostenidas, de hecho, más bien hace un énfasis en el silencio que ambos personajes sostienen. Otro elemento importante de destacar, que marca un primer cambio en el narrador, es que ha dejado de contar la cantidad de tragos y ahora cuenta la cantidad de giros que ha hecho el otro personaje en el taburete, actividad que le molesta, sin embargo, no se atreve a pedirle que deje de hacerlo.

En el giro número quince, el narrador decide hablarle, pero no con ánimo de conversación, sino con tono imperativo: "Y, con toda la serenidad que daban mis palabras medidas, con toda la tensión de mi rostro bañado en sudor, con toda la convicción de saber que si me iba a casa el dolor me acabaría, le pedí que por favor dejara de joder con el maldito asiento" (Arroyo, 1998: p. 115). Este acto, hablarle, le da al hombre de talla baja una suerte de "derecho de respuesta", de alguna manera el protagonista ha caído en su trampa, pues lo ha intentado ignorar hasta ese punto, sin embargo, en ese momento da cuenta de que no lo ha logrado, más bien, ha sido todo lo contrario, es evidente su presencia.

El enano pretende hablar, pero es ignorado nuevamente, su voz silenciada y su persona invisibilizada. Dicho en palabras de Villoro, el protagonista continúa en el primer estadio:

[...] entonces me miró con su sonrisa traviesa y dijo algo. Y como lo más lejos de mi mente estaba el entablar diálogos con nadie, mucho menos con gnomos en cantinas, pretendí que no me había hablado y seguí atento al cantinero en sus demostraciones artísticas (Arroyo, 1997: p. 115).

Sin embargo, este segundo hombre le echa mano a lo más humano que tiene: su voz. En este punto, aparece el concepto de voz según lo describe Bajtín, como el entrecruzamiento entre el sistema lingüístico y el sistema ideológico. 
Explica Tatiana Bubnova que "En el mundo de Batín, la escritura no se privilegia sino justamente como un recurso capaz de traducir las (sic) voz humana en la medida en que es portadora de los sentidos de la existencia, preservando de un modo específico sus modalidades, que él caracteriza mediante metáforas relacionadas con la voz y la música" (Bubnova, 2006: 100). En este mismo texto, Bubnova explica que Bajtín prefigura la filosofía dialógica, pues al acto el habla le añade otro ingrediente decisivo, constituyente de lo humano, que es la palabra, que para el ser humano siempre ha estado ahí, como el otro:

Pero lo más importante es que las palabras pueden existir únicamente en forma de diálogo, lo mismo que el sujeto, el yo, sólo existe en una interacción con el otro que le da origen en el momento de dirigirle palabra por medio de un tú, para que podamos reconocer humildemente: yo también soy (Bubnova, 2006: 104).

Explica Helena Beristáin en el Diccionario de Retórica y Poética que el diálogo es más bien característico de los relatos teatrales. En el texto en estudio sobresale el hecho que estesegundopersonaje, elenano, logreinterrumpiralnarradorprotagonistaegocéntrico, quehastaestemomentonos hacontadoanosotros, comolectores, todoloquehaocurrido:

Pero de su lado seguía la voz, una voz que parecía dirigida a algún interlocutor invisible delante de él, aunque yo sabía que me hablaba a mí, con la curva exacta entre su sonido y mi oído. Y fue así como empecé a captar sílabas y palabras en un fraseo elegante, como un discurso aprendido y repetido hasta el virtuosismo. Pero además, al no atreverme a mirarlo, en el sólo hecho de dejarlo hablar, me daba cuenta de que cedía terreno ante él, por más que mantuviera la vista adelante y pretendiera que no existía (Arroyo, 1998: p. 115).

Hasta este momento, el protagonista ha ignorado, invisibilizado y silenciado a este segundo hombre debido a que conversar con el Otro es una forma de "ceder el terreno". En el encuentro con el Otro, una de las razones primordiales para no entablar una relación o una conversación es ese temor al Otro, el conocer a un ser diferente de lo que los prejuicios y estereotipos han dictado en la lectura inicial. Al principio del texto, el protagonista es descrito como un ser egocéntrico; sin embargo, en este punto del cuento, aparece, nuevamente en una línea, la siguiente frase potente del texto. Es un punto donde el narrador protagonista cede su espacio y le da voz a este segundo personaje, quién nos dice (a los lectores) directamente lo siguiente: 
Leer, asumir y etiquetar al Otro...

“¿Dolor--me decía. --¿Quieres saber de dolor?Yosípuedo hablar de dolor”

Aquí, es necesario destacar el hecho de que el hombre de talle bajo logra tener una voz tan fuerte que interrumpe al narrador en su historia. Sin embargo, en este punto el narrador, discursivamente, sigue en el mismo lugar, es decir, en el mismo estadio de reconocimiento del Otro, pues piensa que ese comentario está relacionado con él:

Por un momento pensé que estaba conjeturando sobre algún mal mío, algo corporal que se manifestaba en mi abundante sudor y mi incapacidad de emborracharme. Por eso consideré seriamente irme al otro extremo de la barra, en donde había una pareja de enamorados concentrada en tocarse (Arroyo, 1998: p. 116).

El enano continúa hablando, nuevamente el narrador le da espacio a su voz directamente. En este punto, se abre el espacio donde este segundo personaje describe su mundo donde abunda la exclusión y cómo él ha sido leído toda su vida:

--Yo conozco el dolor desde que tengo uso de razón --continuó el enano, hablando con el interlocutor invisible que era yo. --¿Crees que es poca cosa pasar la vida como enano? ¿Crees que esta sonrisa vino fácil? Es una educación, mi adaptación a la insensibilidad de ustedes, los normales. Mi maquillaje para demostrarles que tolero su crueldad a cambio de que sean menos crueles. Un recurso, en otras palabras, corno esos animales que esconden el rabo entre las piernas o se hacen pequeños ante los más poderosos (Arroyo, 1998: p. 116).

De la descripción anterior, sobresalen varias partes que vale la pena destacar. La primera, es el tema de la sonrisa: al exponer su mundo muestra que es sumamente pesado cargar con un estereotipo; sin embargo, es la forma de sobrevivir en un mundo que lo excluye. Por otro lado, es muy llamativa la frase cuando habla de "ustedes, los normales"; es evidente que él no se considera dentro de ese grupo, lo cual deja ver dos elementos: primero, la división dicotómica de la sociedad: los normales y, por lo tanto, los no-normales o anormales. Dicho de otro modo, hay una clara división entre nosotros y los otros, y evidentemente él pertenece a este segundo grupo. Por otra parte, "los normales" tampoco son buenos seres humanos, pues su característica más sobresaliente es el ser crueles, por lo que "los otros" deben adaptarse a calzar en lo esperado para sobrevivir, es decir, deben internalizar esa otredad.

En este punto, el narrador ha experimentado un pequeño cambio, pues escucha al 
segundo hombre. Aunque, todavía no ha cambiado la forma en que lo lee, pues todavía se sigue situando en "el lugar privilegiado del sujeto que habla" como diría Foucault. En palabras de Villoro, empieza a verse el umbral del segundo estadio, aunque todavía no lo ha cruzado:

En este punto tuve que aceptar que él había empezado ganando, porque era cierto, yo nunca me he imaginado pequeño, ni siquiera de mediana estatura. Con mi metro noventa no hay quien no se entere de que he llegado a un sitio, y existen cosas que siempre he tomado por descontado, como el mirar a los demás desde arriba o el convivir con este cuerpo que algunos califican hasta de "imponente" (Arroyo, 1998: 117).

En la cita anterior aparece la autodescripción del narrador, quién con su cuerpo se considera imponte, con lo cual marca una clara distancia con el otro, pues hay por lo menos medio metro de diferencia entre ellos. El narrador acostumbra mirar a los otros desde arriba, por lo tanto, ser mirado desde abajo. Esta forma de mirar recuerda a la técnica cinematrográfica de picada y contrapicada: el narrador acostumbra a mirar a los otros de picada, es decir hacia abajo, y esta técnica es utilizada en el cine para minimizar a un personaje; dicho de otro modo, él está acostumbrado a disminuir a los demás. Mientras, por el contrario, enfocar a un personaje hacia arriba lo que hace grandioso, esa es la forma en la que el narrador acostumbra ser visto por los otros, de ahí su megalomanía. Por esta razón piensa lo siguiente:

Pero en este punto me dije que el hombrecito sufría de miopía, porque mi dolor nada tenía que ver con algo físico. Ojalá lo fuera.

--Físico o mental, es lo mismo --dijo de repente, la vista adelante, con lo que logró que por poco me ahogara con mi trago, al pensar que me leía el pensamiento. (Arroyo, 1998: p. 117).

El narrador sigue todavía en el primer estadio, según Villoro. Es el mismo lugar de lectura del otro, y sigue siendo el mismo egocéntrico del principio, pues no se le ocurre pensar que el hombre de talla baja está hablando de su experiencia personal. Sin embargo, sí es notable un pequeño cambio, chiquito pero cambio: escucha lo que el otro le está diciendo. La voz del segundo hombre es tan fuerte que puede seguir interrumpiendo al narrador de esta historia. A continuación, aparece el discurso del segundo hombre donde deconstruye y 
Leer, asumir y etiquetar al Otro...

desarticula el estereotipo con el cuál el narrador lo ha etiquetado desde el principio. Y, también, le ofrece una lectura del cantinero, muy distinta a la que el narrador presentó desde el principio:

--Todo está unido, y sólo Dios sabe cómo he tenido que luchar para que mi mente no se fuera detrás de mi figura. Todo el mundo piensa que los enanos somos los seres más divertidos de la tierra. Todos nos imaginan de un buen humor permanente, y por eso nos ofrecen trabajos en circos. Es un estereotipo, como el que le aplican a los gordos, como nuestro amigo allá enfrente, el cantinero, que en realidad es un malhumorado que esconde su verdadera naturaleza tras su fachada de bonhomía.

Porque si la gente supiera cómo envidia a los delgados y a través de ellos a la humanidad entera, nadie le daría trabajo y mucho menos en una cantina. Los gordos, como los enanos, derrochamos una alegría que pagamos en privado, cuando nadie nos ve y nos contemplamos en el espejo (Arroyo, 1998: p. 117).

Nuevamente, el narrador comenta que jamás imaginó el mundo que le describe este hombre de talle bajo y de hecho, la pintura que le hace del cantinero está más cercana a la realidad que la que él mismo imaginó: "viendo al cantinero delante de mí, gordo entre los gordos, puedo captar algo de lo que dice el enano, cuando por encima de su rostro afable se le cuela un gesto que traiciona su violencia reprimida" (Arroyo, 1998: p. 118). Aquí, ya aparece un cambio más notorio en el narrador, pues empieza a darle la razón al enano. Pues lo que el narrador consideraba y pensaba no concordaba con lo que sucede. De otra manera dicho, el proceso de leer, asumir y etiquetar al Otro que ha venido haciendo el narrador le da conclusiones erróneas. La función del cantinero, como tercer personaje de esta historia, es fundamental para que tanto el narrador como el enano puedan mirarlo y hacer lecturas distintas.

En el cuento, seguidamente aparece un largo discurso del segundo hombre, donde cuenta cómo conoció a su esposa en el circo. El narrador lo escucha simplemente poder comparar el dolor: "a estas alturas de su conversación yo tenía que conocer su dolor. Para ver si remotamente se comparaba con el mío" (Arroyo, 1998: p. 118), pero también acepta que escucharlo le produce "una sensación extraña". De la historia del enano destacan ciertas palabras que muestran cómo este ha interna- 
lizado ese "ser-otro", así como su esposa también. Primero, el hecho de ser exhibidos en un circo, pero tener que sonreír y soportar las burlas por su romance, particularmente "cuando todos se opusieron a nuestro matrimonio los curas, los médicos y los trabajadores sociales, quienes nos tildaban de egoístas, reclamándonos que íbamos a traer al mundo más gente deformada" (Arroyo, 1998: p. 118). Es destacable esta última palabra, no son vistos como seres humanos, sino como seres deformes. Esto explica el gran dolor interno y la insistencia sobre el tema del dolor.

Finalmente, cuando consiguen un cura que los case, a la boda solo asisten los enanos del circo, y "no asistió ninguno de los normales, quienes de esta forma demostraban su hostilidad por lo que consideraban degeneración nuestra. Aunque para los normales cualquier experiencia de los enanos es grotesca" (Arroyo, 1998: p. 119). Sumado a la palabra deforme, también aparecen los adjetivos degenerado y grotesco. En la Biología, la degeneración se da cuando una célula o un tejido se deterioran funcionalmente. Y, lo grotesco está asociado a lo irregular, lo grosero y de mal gusto. Todas estas palabras en cualquier otro contexto son insultos, sin embargo, este segundo hombre y su esposa deben convivir diariamente con ellas y todas sus acciones o actividades ser tachadas, literalmente, de esa manera. Nuevamente, se recalca la diferencia con "los normales". $\mathrm{E}$

1 enano continúa contando su historia, de cómo en esta vida solo ha sentido amor por su esposa, por ser su espejo; nunca por las "mujeres normales". Hasta que su esposa queda embarazada y la dicha que representa esta situación es aprovechada por los dueños del circo, pues su esposa debe sonreír "al exhibir su maternidad como otra curiosidad, su barriga un enigma que el público podía resolver con todo tipo de especulaciones. Nosotros, ella y yo, sólo sonreíamos. Dolor, yo sí sé de dolor” (Arroyo, 1998: p. 119).

Y en este punto ocurre un cambio realmente significativo en el narrador: el cantinero les trae otro trago, y al hacerlo "nos miraba, alternativamente, como diciéndose que esta noche le había tocado la gente más rara del mundo". Esa primera persona plural sí incluye al segundo hombre, pues el narrador, aunque bajo protesta, ha estado escuchando la historia que le están contando y se ha interesado en ella: le ha cambiado su perspectiva y lo ha movido en su lugar de discurso. Ahora, el narrador se identifica con "lo raro", y en ese lugar, se encuentra con el enano. De alguna manera, el bar continúa en su dinámica convencional, pero ellos, son distintos. 
En narrador al contar esta parte insiste en "nuestra esquina" y que el cantinero reconoce "en nosotros a los clientes más tranquilos del lugar".

Ya en este cambio, el segundo hombre cuenta el resultado de la historia:

--Hasta cuando la barriga de mi mujer pasó de chiste a seriedad. Porque en los últimos meses adquirió tal volumen que se podría jurar que era más ancha que alta. Le era imposible todo: caminar, sentarse o acostarse. Y por primera vez hubo algo parecido a solidaridad entre los compañeros del circo, normales o no, cuando vieron a mi mujer sufrir, cuando dejó de sonreír. Porque lo que estaba creciendo en su barriga eran gemelos (Arroyo, 1998: p. 120).

El dolor humano hermana, eso es lo que destaca el enano en esta parte. Y es exactamente lo mismo que está ocurriendo entre el narrador y el hombre que entró en el whisky número veinte. El narrador egocéntrico del principio, que quería estar solo para anestesiar su propio quebranto, se encuentra con alguien cuyos duelos son más violentos, profundos y dolorosos. El permitir la voz del otro, que cuente su perspectiva en lugar de asumirlo y etiquetarlo, le cambia totalmente su propia visión de mundo, y el cuento es muy consistente en esto: "El bar, el cantinero, los novios y el resto de los parroquianos se me presentaron en toda su realidad es decir, en toda su fealdad" (Arroyo, 1998: 120). Esta última cita muestra el cambio que ha tenido el narrador, quién al principio encontraba la belleza en las botellas y la música del bar, es decir, en la dinámica propia. El escuchar la historia del otro, aunque fuera con la intención de compararla con la suya, le abre un mundo distinto, un mundo que nunca había visto. Es decir, en este punto, en narrador egocéntrico del principio se ha movido en su lugar de discurso, ahora se ubica e identifica con "los raros" y ahí lee un mundo-otro.

Mientras la borrachera iba y volvía, y el cantinero seguía trayendo los tragos, pero sin cruzar una palabra, el segundo hombre da su estocada final:

--Las radiografías los mostraban claramente, un varón y una hembra

--continuó el duende. -Pero con un tamaño descomunal, como si fueran gigantes. Entonces, temiendo por su vida, aceptamos una cesárea. Dejó de hablar y vació el contenido de su vaso. Yo me agarré de la barra ante el temor de otro súbito ataque de sobriedad. Entonces, con su mayor sonrisa traviesa de la noche, me dijo:

--Murieron los tres en el parto. Yo sí sé de dolor (Arroyo, 1998: p. 121). 
Es hasta la última frase del texto que el lector se da cuenta que el segundo hombre ganó esta contienda, que sólo existía en la mente del narrador. El cuento termina, cuando el segundo hombre se columpia frenéticamente en el taburete y con su sonrisa maliciosa le decía la frase que ha venido repitiendo por toda la noche: “¿Dolores a mí”. Por primera vez se escucha la voz del cantinero, pero es una voz que los echa del bar, nuevamente el narrador insiste en la primera persona plural: "nos gritó". Al final del texto vemos un narrador totalmente distinto al del principio, el narrador insistía en su interés de estar solo, pero ahora "Pedí las cuentas y cancelé. Entonces, completamente sobrio y sin el menor dolor, invité a mi amigo a otro bar" (Arroyo, 1998: p. 122).

\section{Palabras Finales}

Cuando Seymor Menton comenta el cuento antologado en la novena edición del texto El cuento hispanoamericano (2007) dice lo siguiente: "En pocas páginas, el autor logra convertir una situación común y corriente, una situación cotidiana, una situación insignificante en una batalla dramáticas cargada de tensión" (Menton, 2007: 723). Estas mismas palabras pueden decirse de "Héroes a medio tiempo", pues un aparente mal de amores (pues el texto no da mayores indicios) lleva a un protagonista egocéntrico a un bar con la intención de ahogar las penas en alcohol. Pero la llegada de un enano que cuenta su historia, y que el otro escucha, le abre una lectura distinta del mundo. El bar pierde su encanto porque en el nuevo mundo lo hermana al dolor del otro. El hombre corpulento e "imponente" del principio cruza al final el tercer estadio del reconocimiento del otro, según la teoría de Villoro.

Y, por otra parte, también este cuento, desborda la construcción del Otro, pues si bien el narrador se ubica en un inicio en una posición de discurso que ve al otro como un inferior, al final lo termina respetando y logra encontrar una igualdad en el dolor y la humanidad compartida. Tal vez en esto radica lo heroico que aparece en el título, que como programador de lectura nos presenta una historia en medio tiempo. Del título a la última línea: el dolor humano hermana, el dolor los hace amigos. Y, ¿por qué medio tiempo? Se podría leer desde la idea de parcialidad, pero también como la idea del tiempo intermedio que tienen ciertos deportes, como por ejemplo el futbol; por lo tanto, los lectores nos encontramos con que hubo una historia antes, presenciamos el medio tiempo, y sabemos que continuará una historia después. 
Por último, la narrativa se caracteriza por el contar historias; de alguna manera le pide prestado al drama los diálogos. El cuento en estudio está contado por un narrador protagonista egocéntrico y despechado que quiere estar solo para rumiar su propia historia. Pero es el elemento de la voz que obliga al diálogo, la que le da un vuelco a este texto, pues donde aparece un diálogo, forzado al principio, pero que mueve en su lugar de discurso al "imponente" narrador, pues sale del bar sobrio, sin dolor y con un nuevo amigo.

Mempo Giardinelli en el prólogo del libro Héroes a medio tiempo, el cuentario, rescata de la pluma de Justo Arroyo "la brevedad, concisión, singularidad temática, tensión e intensidad" (Giardinelli, 1998: p. IX). Por lo que de este cuento puede rescatarse las frases cortas que son supremamente contundentes y logran darle giros sorprendentes a la historia. Siguiendo el esquema de aristotélico, aunque este lo piensa en términos del drama, este cuento tiene cinco puntos que amarran la historia. En este cuento, aunque está narrado como una historia, parece una obra de teatro que se podría dividir en cinco actos: el primero cuando el narrador toma solo con un dolor en el pecho. El segundo acto abre con el segundo hombre que llega en el whisky número veinte. El tercer acto es la descripción del mundo del enano y la lectura que hace del cantinero. El cuarto acto es la historia de amor y dolor entre el enano y su esposa. El quinto y último acto se da a partir de que el enano cuenta cómo muere su esposa y los echan al narrador y el enano del bar, que sería la resolución del texto.

\section{Nota}

1 Los destacados no están en el texto original

\section{Referencias}

Arroyo, J.. (1998). Héroes a medio tiempo. Panamá: Universidad Tecnológica.

Beristáin, H.(1995). Diccionario de Retórica y poética. Sétima edición. México: Editorial Porrúa. 
Bourdieu, P. (1999). "El orden de las cosas" en BOURDIEU, P. (director). La miseria del mundo. Argentina: Fondo de Cultura Económica.

Bubnova, T. (2006). "Voz, sentido y diálogo en Bajtín”. Acta Poética. 27 (1). Primavera. 97-114.

Cuentos panameños: antología de narrativa panameña contemporánea. (2004). Segunda edición. España: Editorial popular.

Giardinelli, M. (1998). "Prólogo: Los nuevos cuentos de Justo Arroyo" en Justo Arroyo (1998). Héroes a medio tiempo. Panamá: Universidad Tecnológica.

Mackenbach, W. (2004). Cicatrices: un retrato del cuento centroamericano. Nicaragua: Anamá Editores.

Menton, S. (2007). El cuento hispanoamericano. Novena edición. México: Fondo de Cultura Económica.

Pickering, J. y Durham L. (1988). Reader's Guide to the Short Story to accompany Fiction 100: anthology of Short Stories. Macmillan Publishing Company: New York.

Villoro, L. (1998). "Estadios en el Reconocimiento del Otro" En Estado plural, pluralidad de culturas. México: Editorial Paidos.

\section{¿Cómo citar este artículo?}

Longan Phillips, S. (Enero-junio, 2018). Leer, asumir y etiquetar al Otro: una lectura de "Héroes a medio tiempo" de Justo Arroyo. Revista humanidades, 8(1), 137-151. doi: http://dx.doi.org/10.15517/h.v8i1.31475 